\title{
Realistic plant species losses reduce invasion resistance in a California serpentine grassland
}

\author{
Paul C. Selmants ${ }^{1 *}$, Erika S. Zavaleta ${ }^{1}$, Jae R. Pasari ${ }^{1}$ and Daniel L. Hernandez ${ }^{2}$ \\ ${ }^{1}$ Environmental Studies Department, University of California, Santa Cruz, CA 95064; and ${ }^{2}$ Department of Biology, \\ Carleton College, Northfield, MN 55057, USA
}

\begin{abstract}
Summary
1. The majority of experiments examining effects of species diversity on ecosystem functioning have randomly manipulated species richness. More recent studies demonstrate that realistic species losses have dramatically different effects on ecosystem functioning than those of randomized losses, but these results are based primarily on microcosm experiments or modelling efforts.

2. We conducted a field-based experiment directly comparing the consequences of realistic and randomized plant species losses on invasion resistance and productivity in a native-dominated serpentine grassland in California, USA. The realistic species loss order was based on nested subset analysis of long-term presence/absence data from our research site and reflects differing species sensitivities to prolonged drought.

3. Biomass of exotic invasive plant species was inversely related to native species richness in the realistic loss order. In contrast, invader biomass was consistently low across species richness levels in the randomized species loss order, with no effect of native species richness on invader biomass among randomized assemblages. Although total above-ground plant biomass increased with soil depth (a proxy for resource availability) in both realistic and randomized assemblages, soil depth influenced invader biomass only in the randomized assemblages.

4. Synthesis. Our results illustrate that the functional consequences of realistic species losses can differ distinctly from those of randomized species losses and that incorporation of realistic species loss scenarios can increase the relevance of experiments linking biodiversity and ecosystem functioning to conservation in the face of anthropogenic global change.
\end{abstract}

Key-words: biodiversity, community structure, ecosystem functioning, exotic species, invasion ecology, non-random species losses, species loss order, species richness

\section{Introduction}

Accelerating human-caused declines in biodiversity at both local and global scales have prompted concern over the functional consequences of species losses in natural ecosystems (Chapin et al. 2000; Millennium Ecosystem Assessment 2005). Over the past 20 years, many manipulative experimental studies have demonstrated causal linkages between species richness and a wide variety of ecosystem processes including productivity, resource use and resistance to invasion (as reviewed in Hooper et al. 2005; Cardinale et al. 2011). However, the majority of manipulative biodiversity-ecosystem functioning (BEF) experiments have relied on randomized species composition and, to a lesser extent, equalized species abundances within richness levels (Hooper et al. 2005; but see Zavaleta \& Hulvey 2004; Losure, Wilsey \& Moloney 2007; Bracken et al.

*Correspondence author. E-mail: selmants@ucsc.edu
2008 as counterexamples) - features that are valuable for informing ecological theory but do not reflect observed patterns of community composition or species loss in real ecosystems (Duffy et al. 2009).

A tacit assumption of manipulative BEF experiments using randomized species assemblages is that all species within an ecosystem are equally susceptible to decline or local extinction. In reality, however, diversity losses disproportionately involve species with particular functional traits that reflect evolutionarily derived strategies of resource capture and species interaction (Zavaleta et al. 2009). In addition, not all species contribute equally to the functional diversity of a community. The loss of rare species may have functional consequences disproportionate to their biomass (Zavaleta \& Hulvey 2004), and shifts in dominance may alter ecosystem functioning in a manner very different from changes in richness alone (as reviewed in Hillebrand, Bennett \& Cadotte 2008). It follows that the real-world consequences of human-caused biodiversity losses 
may differ systematically from the consequences of randomized biodiversity changes in equal-abundance assemblages that typify most experimental BEF studies.

Most experimental BEF studies also minimize or eliminate environmental heterogeneity among assemblages (but see Dimitrakapoulos \& Schmid 2004 as a counterexample), either through active manipulation of substrate or by the small spatial scale of the experiment (Cardinale et al. 2011). Diversity effects from experiments conducted under homogeneous environmental conditions may underestimate the functional consequences of species losses in real ecosystems because greater environmental heterogeneity provides more niche opportunities, allowing species to exploit resources more completely (Dimitrakapoulos \& Schmid 2004; Cardinale 2011). Moreover, environmental heterogeneity leads to variation in resource availability, which may alter or even overwhelm the effects of species diversity on ecosystem functioning. This has led some to question, in particular, the generalizability of BEF findings that do not address the interactive effects of species richness and resource availability on ecosystem functioning (Davis, Grime \& Thompson 2000; Stachowicz et al. 2002; Renne, Tracy \& Colonna 2006).

Recently, the importance of conducting more realistic BEF experiments has been recognized (Naeem 2008; Hillebrand \& Matthiessen 2009), and the few studies published have demonstrated that realistic species losses may have strikingly distinct functional consequences from randomized losses (Solan et al. 2004; Zavaleta \& Hulvey 2004, 2007; Bunker et al. 2005; Bracken et al. 2008). Most of these studies have relied on either modelling approaches (Solan et al. 2004; Bunker et al. 2005) or isolated experimental microcosms (Zavaleta \& Hulvey 2004, 2007; Schläpfer, Pfisterer \& Schmid 2005; Bracken et al. 2008) to predict the functional consequences of realistic biodiversity losses. While these approaches are important steps towards improving our understanding of how real-world species losses affect ecosystem structure and function, field-based studies are necessary to assess how functional consequences of realistic versus randomized species losses differ in the context of multiple, and often interacting, environmental factors.

Here, we present the results of a field-based experiment directly comparing the consequences of realistic and randomized plant species loss scenarios on invasion resistance and productivity in a native-dominated serpentine grassland of high conservation value in California, USA. Our realistic species loss scenario is based on nested subset analysis of long-term presence/absence data at our research site and reflects differing species sensitivities to prolonged drought, which has been shown to strongly affect community composition and reduce plant diversity in grassland ecosystems (Tilman \& El Hadi 1992; Hobbs, Yates \& Mooney 2007). In addition, our design incorporates environmental heterogeneity in the form of variation in soil depth, an abiotic factor highly correlated with productivity and resource availability in serpentine grasslands in particular (Whittaker 1954; Davies et al. 2007; Moore \& Elmendorf 2011) and grassland ecosystems in general (e.g. Baer et al. 2003; Dornbrush \& Wilsey 2010).
Our study is designed to test two fundamental research questions: (i) How do invasion resistance and productivity change in response to realistic versus randomized plant species losses? (ii) How does variation in soil depth, a form of environmental heterogeneity, affect the relationship between species richness and ecosystem functioning in both the realistic and randomized species loss orders?

\section{Materials and methods}

\section{STUDY SITE}

We conducted this experiment at Coyote Ridge, a grassland reserve located on a 3000-ha serpentine outcrop in Santa Clara County, California $\left(37^{\circ} 15^{\prime} \mathrm{N}, 121^{\circ} 45^{\prime} \mathrm{W}\right)$. Coyote Ridge is an area of high conservation value because it is home to a diverse fauna and speciose, endemic-rich flora, and it serves as a refuge for several native plant and animal species listed as threatened or endangered by the US Fish and Wildlife Service such as the bay checkerspot butterfly Euphydryas editha bayensis (Weiss 1999). The study area is in the central Coast Range of California and experiences the warm, dry summers and cool, wet winters typical of this Mediterranean climate. Mean monthly air temperature was $\sim 14.5^{\circ} \mathrm{C}$ and total precipitation was $570 \mathrm{~mm}$ during the November 2009-April 2010 growing season based on data from an on-site weather station installed 18 March 2009 .

\section{EXPERIMENTAL DESIGN}

Our experimental site was an $800-\mathrm{m}^{2}$ area on a relatively flat ridge top at $356 \mathrm{~m}$ elevation. This area was chosen for its large variation in soil depth within a relatively small area after an exhaustive survey using a graduated cylindrical steel rod ( $1 \mathrm{~m}$ long, $1 \mathrm{~cm}$ diameter) to systematically measure soil depth. Initial measurements revealed areas of consistent soil depth at three levels: shallow $(10-15 \mathrm{~cm})$, medium $(15-30 \mathrm{~cm})$ and deep $(>30 \mathrm{~cm})$. We then conducted more intensive sampling to locate three replicate blocks at each of these three depths large enough in area to encompass 14-17 circular plots of $58 \mathrm{~cm}$ diameter. We chose this plot size because it allowed us to include hundreds of individual plants per plot while allowing a large number of plots to be located within a relatively small area (Hooper 2011). The experimental area was fenced above and below ground to exclude cattle, gophers, pigs and other large mammals, and the area between blocks was mowed in April 2009 to minimize seed rain. Within each plot, we removed standing dead biomass by hand and perennating organs of perennials (e.g. bulbs, rhizomes) by excavation with a trowel down to a depth of $10 \mathrm{~cm}$.

Each block contained plots randomly assigned to each of two loss orders (defined in detail below), one realistic and one random, each with richness levels of 2, 5, 8 and 12 species. Each block also contained a plot with the full experimental species pool (16 species). Remaining plots in each block were reserved for bare (no vegetation) plots and monocultures, neither of which figured in the current analysis. All plots had an equal target number of individual plants, set at $1285 \mathrm{~m}^{-2}$ based on field plant density observations at this site, and all species were planted at relative abundances observed in the field at this site (Table 1). The relative abundance of a given species was not fixed across treatments but increased or declined with diversity as observed in the field (sensu Zavaleta \& Hulvey 2004). The use of field-based abundances allowed us to assess species contributions to ecosystem functioning at realistic abundances. 
Table 1. Species composition and stem targets per plot at each richness level in the realistic loss order treatment. Plant species are listed in reverse order of their loss position

\begin{tabular}{|c|c|c|c|c|c|c|c|}
\hline \multirow[b]{2}{*}{ Species } & \multicolumn{5}{|c|}{ Richness level (no. of species) } & \multirow{2}{*}{$\begin{array}{l}\text { Active } \\
\text { season }\end{array}$} & \multirow{2}{*}{$\begin{array}{l}\text { Functional } \\
\text { group }\end{array}$} \\
\hline & 2 & 5 & 8 & 12 & 16 & & \\
\hline Nassella pulchra & 324 & 158 & 72 & 47 & 45 & Late & Perennial grass \\
\hline Chlorogalum pomeridianum & 48 & 24 & 9 & 7 & 7 & Late & Perennial forb \\
\hline Calystegia subacaulis & & 23 & 18 & 15 & 14 & Late & Perennial forb \\
\hline Muilla maritima & & 20 & 10 & 7 & 8 & Late & Perennial forb \\
\hline Plantago erecta & & 146 & 132 & 81 & 64 & Early & Annual forb \\
\hline Lessingia nemaclada & & & 11 & 7 & 6 & Late & Annual forb \\
\hline Vulpia microstachys & & & 87 & 61 & 42 & Early & Annual grass \\
\hline Microseris douglasii & & & 33 & 19 & 14 & Early & Annual forb \\
\hline Lasthenia californica & & & & 55 & 67 & Early & Annual forb \\
\hline Hesperevax sparsiflora & & & & 67 & 71 & Early & Annual forb \\
\hline Eschscholzia californica & & & & 5 & 4 & Early & Perennial forb \\
\hline Calandrinia ciliata & & & & 4 & 2 & Early & Annual forb \\
\hline Layia gaillardiodes & & & & & 8 & Early & Annual forb \\
\hline Lotus subpinnatus & & & & & 9 & Early & N-fixer (annual) \\
\hline Cryptantha flaccida & & & & & 6 & Early & Annual forb \\
\hline Hemizonia luzulifolia & & & & & 7 & Late & Annual forb \\
\hline Total & 372 & 372 & 372 & 372 & 372 & & \\
\hline
\end{tabular}

We collected native plant seeds from within $2 \mathrm{~km}$ of the experiment site at Coyote Ridge between April and September of 2009. Seed numbers for each species were based on target stem densities per plot, and conservative estimates of germination rates were based on our own trials. We separated all seeds from attached fruiting material and stored them air-dry at room temperature until planting. In addition to collecting seeds, we also excavated perennating organs (e.g. bulbs, rhizomes) of four perennial species (N. pulchra, C. pomeridianum, C. subacaulis and M. maritima; see Table 1) from within $500 \mathrm{~m}$ of the experiment site and transplanted them into their assigned plots so that the functional contributions of these long-lived species were not represented solely by newly germinated individuals. We transplanted perennating organs during the first 2 weeks of October 2009 and hand-scattered seeds in each plot on 5 November 2009.

\section{REALISTIC AND RANDOMIZED LOSS ORDERS}

We generated a non-random, realistic species loss order based on the examination of within- and across-year variation in plant species presence/absence using vegetation data collected annually at Coyote Ridge from 1991 to 2009 in $0.5 \times 0.5 \mathrm{~m}$ quadrats along seven $50-\mathrm{m}$ transects widely dispersed across the landscape (10 quadrats per transect, 70 quadrats total; S. Weiss \& R. Hobbs, unpubl. data). Within each year, we used nested subset analysis to analyse the meta-community for nested structure and identify the best-fit order of species losses from plots of progressively lower diversity at Coyote Ridge (Atmar \& Patterson 1993; Zavaleta \& Hulvey 2004). We calculated nested temperature using the method of Rodríguez-Gironés \& Santamaría (2006), which provides a measure $T$ of the degree to which species assemblages are nested across sites varying in species richness, with low values of $T$ indicating a high degree of nestedness (Atmar \& Patterson 1993; Ulrich, Almeida-Neto \& Gotelli 2009). We also generated null model communities to assess the non-randomness of nestedness patterns (Miklòs \& Podani 2004).

A meta-community is perfectly nested if species-poor microsites (quadrats) are subsets of progressively more species-rich microsites, and rare or uncommon species are present only in species-rich microsites (Ulrich, Almeida-Neto \& Gotelli 2009). In general, rare and uncommon species are at greater risk of local extinction due to their small population sizes (e.g. Pimm et al. 1995), and non-random, nested patterns of species occurrences along diversity gradients result from some species being more susceptible to environmental stressors than others (e.g. Bracken \& Nielsen 2004). Therefore, a highly nested distribution pattern may indicate a predictable order of species loss from more to less species-rich microsites (Zavaleta \& Hulvey 2004). Nested subset analysis can thus be used as an unbiased, realistic estimate of the order of species loss with no a priori assumptions about the ultimate drivers of species loss.

Plant species assemblages at Coyote Ridge were most nested in $1991(T=17.86, P=0.01)$, and least nested in $1996(T=38.94$, $P<0.001)$. Because interannual variation in precipitation is a major driver of plant community composition in California serpentine grasslands (Hobbs, Yates \& Mooney 2007) and grassland ecosystems in general (Albertson \& Weaver 1944; Tilman \& El Hadi 1992), we used the parameter-elevation regressions on independent slopes model (PRISM; http://prism.oregonstate.edu) to estimate annual precipitation for the years 1960-2009 at Coyote Ridge (Fig. S1). Although annual precipitation in 1991 was only $\sim 16 \%$ below the 50 -year average of $567 \mathrm{~mm}$, it immediately followed the most prolonged drought over the past 50 years (1988-90), in which precipitation was $>40 \%$ below the 50 -year mean for each year (Fig. S1). This suggests the high degree of nestedness in 1991 was driven by prolonged drought in preceding years. Notably, the 2 years with the next highest degree of nestedness after 1991 were $2007(T=21.84, P=0.02)$ and $2008(T=24.72, P=0.01) ; 2007$ had the lowest annual precipitation in the 50 -year period examined (262 mm), and 2008 was also a below-average precipitation year (405 mm, $\sim 30 \%$ below the 50-year mean). The year with the lowest degree of nestedness, $1996(T=38.94, P<0.001)$, was one of the highest rainfall years over the past 50 years $(969 \mathrm{~mm}, \sim 70 \%$ above the 50-year mean; see Fig. S1).

We based our realistic loss scenario on the nested pattern of species occurrences in 1991. In addition to the high degree of nestedness, 
1991 was the year with the lowest species richness at both the quadrat and site scales in our 19-year data set. Four generally abundant species present in at least 17 of the 19 years surveyed were absent in 1991: L. gaillardiodes, L. subpinnatus, C. flaccida and H. luzulifolia (see Table 1). We included these four species as the first group to drop out of our realistic loss order (16 spp. down to $12 \mathrm{spp}$.). The rest of the realistic loss order was based on ranks of the top 12 species from the 1991 nested subset analysis for which we could reliably collect seed. The order of species loss in the realistic scenario (see Table 1) is broadly consistent with species sensitivity to drought in other grassland ecosystems; specifically, annual forbs are, in general, more drought-sensitive than annual grasses or perennials (Tilman \& El Hadi 1992), and rare and uncommon species are most susceptible to drought-induced local extirpation (Albertson \& Weaver 1944).

Rarely, if ever, is there enough information available in a given ecosystem to predict with any degree of certainty which species will undergo local extirpation, in what order and by what mechanism. However, given that climate models predict an increase in the frequency of prolonged drought over the next 20-50 years in coastal California (Dai 2011), we argue that prolonged drought is a plausible driver of future species losses in our study system and that our realistic loss order is an illustrative, data-driven scenario of non-random species losses in this system. We conducted our experiment during a near-average precipitation (i.e. non-drought) year. However, we argue that greater frequency of prolonged drought, as predicted for this area (Dai 2011), could lead to permanent local extirpations of species in the order indicated by our nested subset analysis. These local extinction events would not likely be undone by near-average rainfall the following year. While the non-random order of species losses in our realistic scenario (Table 1) is a data-based projection of what could occur under a particular course of events, it is arguably more likely than the random loss designs typical of most manipulative BEF experiments.

To directly compare our realistic loss order to a random loss scenario, we used the same pool of 16 species (see Table 1) to generate a unique randomized loss order in each of the nine blocks. Species assemblages were constrained to ensure even representation of all 16 species across the nine replicate blocks by stratified random selection with replacement. Specifically, a species could not be chosen for inclusion at a particular richness level within the random loss order for a second time until all other species had been chosen for inclusion at that richness level.

\section{INVASION RESISTANCE AND PEAK ABOVE-GROUND BIOMASS}

After planting, non-target species were removed by hand from all plots on a monthly basis except for two exotic invasive species, Bromus hordeaceus and Lolium multiflorum, which were allowed to establish wherever they germinated. We assumed an equal probability of seed rain from these two exotic invasive species landing in any of our experimental plots because our experiment area was small $(800$ $\mathrm{m}^{2}$ ) and the porous above-ground fence, consisting of three strands of barbed wire and one layer of chicken wire $<1.5 \mathrm{~m}$ in height, likely had small and equal effects between species on wind-dispersed seeds.

We measured percentage cover of all species (natives and exotics combined) in each plot in February of 2009 (mid-growing season) as an estimate of filled niche space in each plot. Five different people independently assessed percentage cover to the nearest $5 \%$ in each plot by visual estimate. We discarded the highest and lowest cover value estimates for each plot and averaged the remaining three estimates. We measured peak above-ground biomass by harvesting above-ground plant parts in each plot on two separate occasions, 22 March and 30 April 2010. In total, we harvested an area of $0.09 \mathrm{~m}^{2}$ (approximately one-third of the plot area), $0.06 \mathrm{~m}^{2}$ in March and $0.03 \mathrm{~m}^{2}$ in April. Biomass was sorted by species in the laboratory, dried at $60{ }^{\circ} \mathrm{C}$ for at least $48 \mathrm{~h}$ and then weighed to determine speciesspecific biomass in each plot.

\section{DATA ANALYSIS}

A direct test of the effects of realistic versus randomized species losses across the full range of species richness in this experiment was not possible because there was only one 16-species plot per block. To confirm that realistic and randomized species losses differed in their effects on invader biomass, total biomass and mid-season cover, we used analysis of covariance (ANCOVA) to directly compare slopes of the two species loss order treatments using only data from the 2, 5, 8 and 12 species plots in each treatment. Where the slopes differed significantly $(P<0.05)$, we then analysed relationships with species richness and soil depth separately for each loss order using a univariate general linear model (GLM) with soil depth as a fixed factor and species richness as a covariate (van Ruijven \& Berendse 2005); we used an alpha level of $P<0.05$ for all statistical tests. Invader biomass data were ln-transformed to satisfy assumptions of normality, linearity and homoscedasticity. Means and standard error values of invader biomass displayed in figures were back-transformed from the natural $\log$. When the main effect of soil depth was significant, we used Tukey's HSD as a post hoc multiple comparisons test among the three depth strata. To assess the effects of native biomass and mid-season cover on invasion resistance, we performed curve-fitting and regression analysis with total exotic invasive plant biomass from the March and April harvests pooled across the two loss orders as a function of either native biomass or total percentage cover in mid-growing season (February 2010). Data were analysed using JMP version 8 (SAS Institute, Inc., Cary, NC, USA).

\section{Results}

All 45 plots within the realistic loss order were invaded by at least one of the two exotic species, and 16 of the 45 realistic loss order plots $(\sim 36 \%)$ were invaded by both exotic species. In the random loss order, 39 of 45 plots were invaded by at least one exotic species $(\sim 87 \%)$ with nine random loss order plots invaded by both exotic species (20\%). Lolium multiflorum was the dominant invader, in terms of both biomass per plot and number of plots invaded. On average, L. multiflorum made up $94 \pm 2 \%$ of invader biomass in realistic loss order plots and $99 \pm 0.5 \%$ in random loss order plots (mean $\pm 1 \mathrm{SE}$ ). The vast majority of plots invaded by a single exotic species were invaded by L. multiflorum; only a single plot, a 12-species assemblage in the realistic loss order treatment, was invaded exclusively by $B$. hordeaceus (invader biomass $=0.13 \mathrm{~g} \mathrm{~m}^{-2}$ ). A notable difference in invasion resistance emerged between realistic and randomized two-species plots. All of the realistic two-species plots, each consisting of the late-season perennials $N$. pulchra and $C$. pomeridianum, were invaded, with invader biomass ranging from 22.9 to $463.5 \mathrm{~g} \mathrm{~m}^{-2}$. In contrast, randomized two-species plots consisting of two annual species resisted invasion entirely; only randomized two-species plots that included a late-season perennial were invaded (range $=0.5-356.8 \mathrm{~g}$ invader biomass $\mathrm{m}^{-2}$ ). 
The slope of the relationship between native species richness (2-12 spp.) and invader biomass differed significantly between the realistic and randomized loss order treatments $\left(F_{1,68}=12.4, P<0.001\right.$; data not shown). In the realistic loss order, exotic plant biomass was inversely related to native species richness (Fig. 1). Despite a positive trend, soil depth had no effect on invader biomass in the realistic loss order, and there was no significant interactive effect of native species richness and soil depth on invader biomass (Fig. 1). In contrast, native species richness had no effect on invader biomass in the randomized loss order, but invader biomass was significantly higher in deep soils than in either shallow or medium soils (Fig. 1). There was no interactive effect of species richness and soil depth in the randomized loss order (Fig. 1).

There was a significant difference between the realistic and randomized species loss order treatments in the relationship between native species richness (2-12 spp.) and total aboveground plant biomass $\left(F_{1,68}=8.3, P=0.005\right.$; data not shown). Total above-ground biomass in the realistic species loss order responded positively to both native species richness and soil depth (Fig. 2). Total above-ground biomass in the randomized loss order also increased significantly with soil depth, but there was no effect of native species richness (Fig. 2). There was no significant interactive effect of native species richness and soil depth on total above-ground biomass in either the realistic or randomized loss order plots (Fig. 2).

The realistic and randomized loss order treatments differed significantly in the relationship between native species richness (2-12 spp.) and mid-season (February 2010) cover $\left(F_{1,68}=5.36, P=0.02\right.$; data not shown). We found a strong positive relationship between mid-season cover and native species richness in the realistic loss order but no response of mid-season cover to native species richness in the randomized loss order (Fig. 3). There was no effect of soil depth or interactive effects of species richness and soil depth on mid-season cover in either the realistic or randomized loss orders (Fig. 3). When combined across the two loss orders, native biomass was a significant predictor of end-season exotic biomass (adj. $R^{2}=0.38, P<0.001$; data not shown). However, mid-season cover across the two loss orders explained a much greater proportion of the variation in end-season exotic species biomass ( $\sim 63 \%$, Fig. 4$)$.
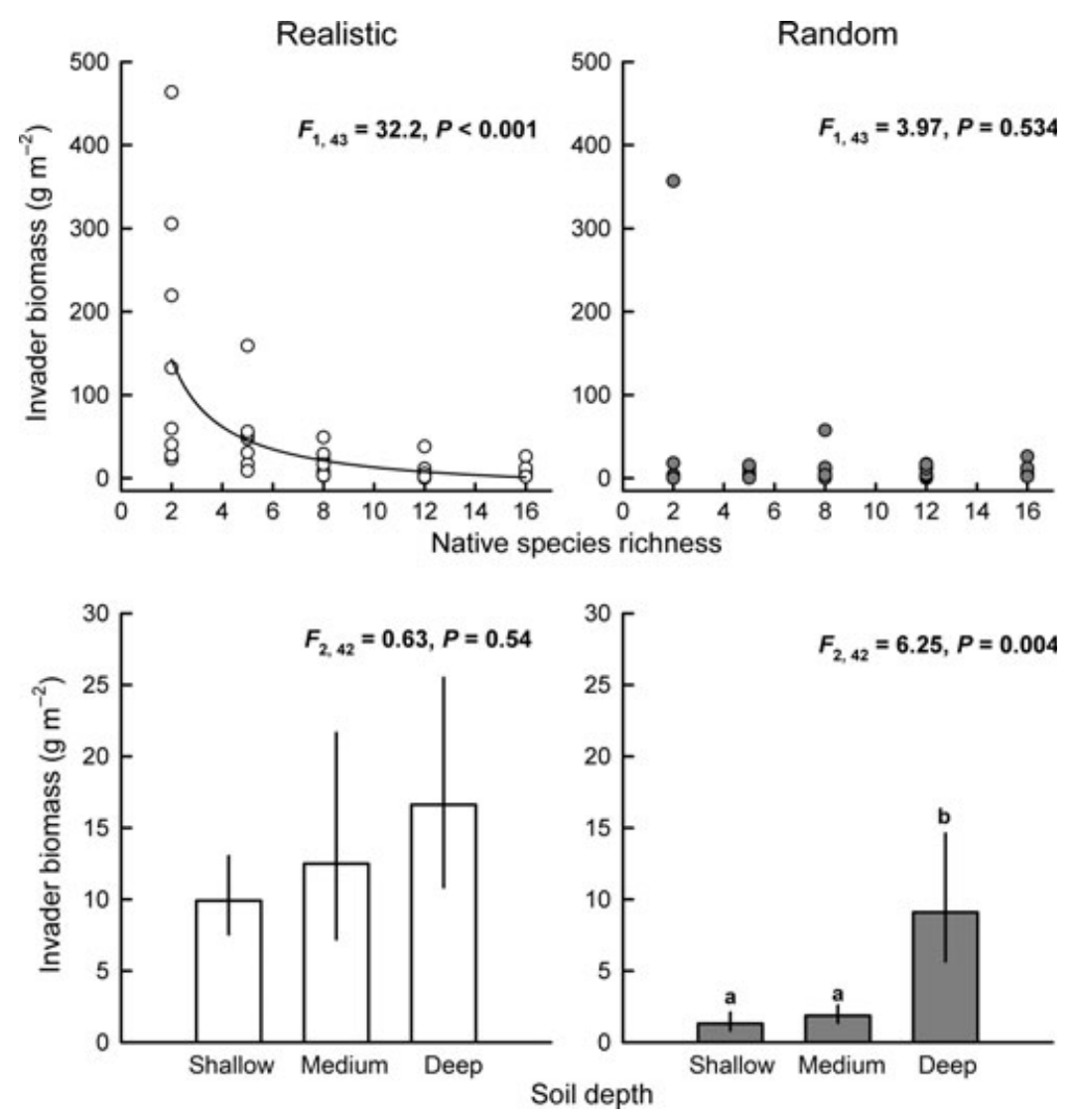

Fig. 1. The influence of native species richness and soil depth on invader biomass in realistic and randomized native species loss orders at Coyote Ridge, California, based on a univariate general linear model (GLM) with native species richness as a covariate (continuous variable) and soil depth as a fixed factor (categorical variable). Data in the upper two panels are individual values, and data in the lower two panels are means and standard errors. Test results are based on ln-transformed invader biomass data for both realistic and randomized species loss orders; means and standard error values displayed in the lower two panels are back-transformed from the natural log. There was no significant interactive effect of native species richness and soil depth in either the realistic or randomized loss orders $\left(F_{2,42}=1.56, P=0.22 ; F_{2,42}=0.75, P=0.48\right.$, respectively). The line in the top left panel represents the best-fit relationship based on the univariate GLM. Error bars in the lower two panels represent one standard error of the mean. Different letters represent significant differences $(P<0.05)$ based on Tukey's HSD tests. 

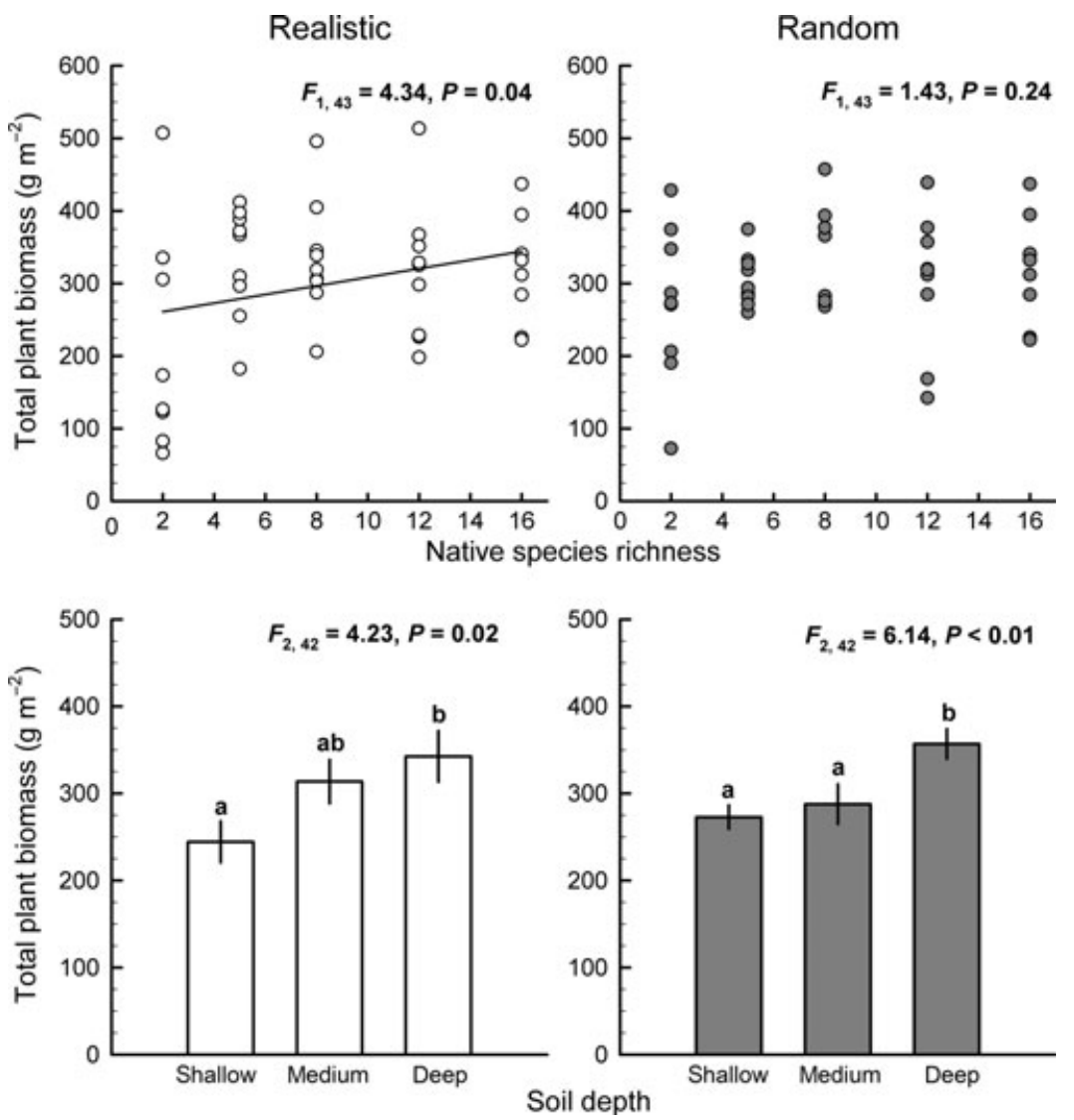

Fig. 2. The influence of native species richness and soil depth on total peak above-ground plant biomass in realistic and randomized native species loss orders at Coyote Ridge, California, based on a univariate general linear model (GLM) with native species richness as a covariate (continuous variable) and soil depth as a fixed factor (categorical variable). Data in the upper two panels are individual values, and data in the lower two panels are means and standard errors. There was no significant interactive effect of native species richness and soil depth in either the realistic or randomized loss orders $\left(F_{2,42}=2.25, P=0.12 ; F_{2,42}=1.24, P=0.30\right.$, respectively). The line in the top left panel represents the best-fit relationship based on the univariate GLM. Error bars in the lower two panels represent one standard error of the mean. Different letters represent significant differences $(P<0.05)$ based on Tukey's HSD tests.

\section{Discussion}

Consistent with other recent experiments and modelling efforts (Solan et al. 2004; Zavaleta \& Hulvey 2004, 2007; Bunker et al. 2005; Schläpfer, Pfisterer \& Schmid 2005; Bracken et al. 2008), we found that the functional consequences of realistic, nonrandom changes in biodiversity differed substantially from the effects of random changes. Specifically, we found that both invasion resistance and productivity declined with realistic species losses but did not respond significantly to randomized species losses. While our results support previous work, our study is the first to directly compare the functional consequences of realistic versus randomized plant species losses under field-based conditions.

Overall, the best predictor of invader success was mid-season percentage cover (Fig. 4), indicating that plots with more available open space early in the growing season allowed earlyseason annual invaders to germinate and establish. Notably, mid-season cover had a strong positive relationship with native diversity in the realistic loss order but did not vary with native species richness in the randomized loss order. This pattern indicates that the realistic species loss scenario led to a greater decline in filled niche space than the randomized species loss scenario and suggests that the order in which plant functional attributes are lost may be an important driver of invasion success. In our realistic loss order, the species that drop out first are primarily early-season annuals, while those that persist to the end of the realistic loss order are late-season perennials (Table 1), a pattern correlated with prolonged drought in this ecosystem and consistent with patterns of species losses due to drought sensitivity in other grasslands (Albertson \& Weaver 1944; Tilman \& El Hadi 1992). These perennial species are slow-growing, long-lived stress tolerators that allocate less of their photosynthate towards above-ground production than early-season annuals (Hooper \& Vitousek 1998; Dukes 2001), thus reducing competition for resources and allowing invaders to establish. The fact that mid-season cover is the best predictor of end-season invader biomass across the two loss orders suggests that early- to mid-season competition for resources (i.e. water, nutrients, light) is a critical factor controlling the successful establishment of invaders in this ecosystem (Losure, Wilsey \& Moloney 2007; Going, Hillerislambers \& Levine 2009; Hautier, Niklaus \& Hector 2009). Further evidence that unfilled niche space strongly controls invasion in this system is 

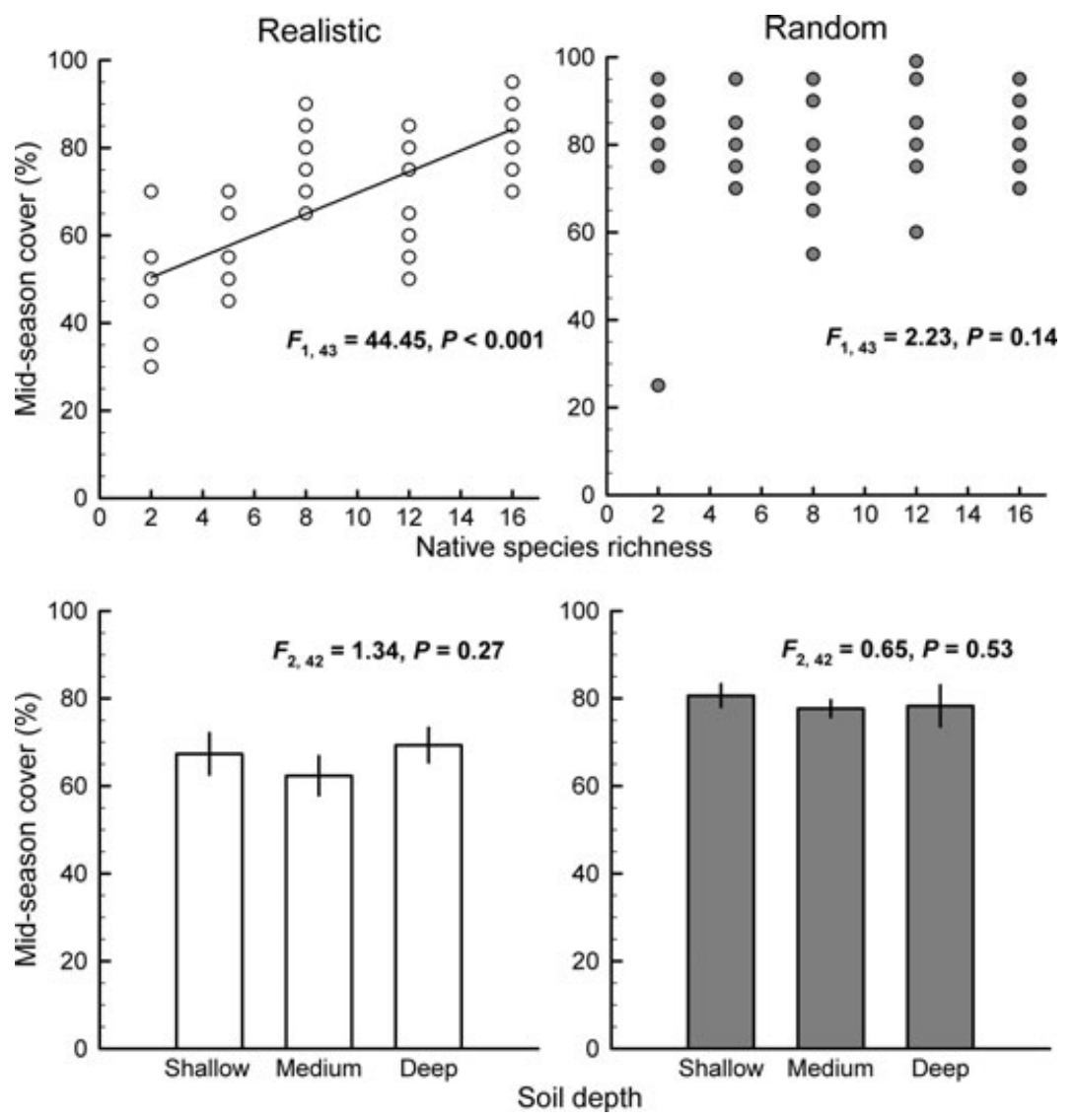

Fig. 3. The influence of native species richness and soil depth on mid-season percentage cover in realistic and randomized native species loss orders at Coyote Ridge, California, based on a univariate general linear model (GLM) with native species richness as a covariate (continuous variable) and soil depth as a fixed factor (categorical variable). Data in the upper two panels are individual values, and data in the lower two panels are means and standard errors. There was no significant interactive effect of native species richness and soil depth in either the realistic or randomized loss orders $\left(F_{2,42}=0.27, P=0.77 ; F_{2,42}=1.02, P=0.37\right.$, respectively). The line in the top left panel represents the best-fit relationship based on the univariate GLM. Error bars in the lower two panels represent one standard error of the mean.

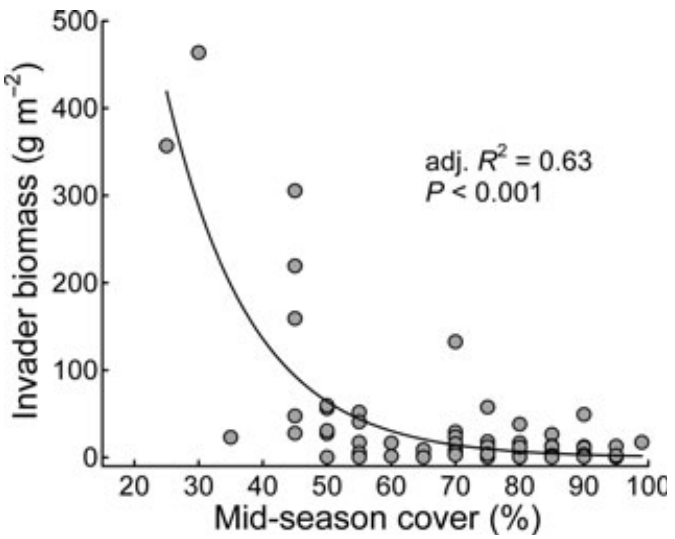

Fig. 4. Mid-season percentage cover of all species (native and exotic) as a predictor of above-ground invader biomass across all levels of species richness and soil depth at Coyote Ridge, California. The line represents the best-fit relationship based on nonlinear regression.

the fact that randomized two-species plots containing two annual species had high cover values and resisted invasion entirely; only randomized two-species plots containing a perennial had low cover values, and each was invaded by at least one of the two exotic species.

More species-rich communities are generally more resistant to invasion when compared at local scales under relatively homogeneous abiotic conditions (Hector et al. 2001; Levine, Adler \& Yelenik 2004; Hooper et al. 2005). The likely explanation is that communities utilize a greater proportion of available resources as richness increases (Elton 1958; Tilman 1999), suggesting that resource availability is a key factor determining resistance to invasion (Davis, Grime \& Thompson 2000; Stachowicz et al. 2002; Renne, Tracy \& Colonna 2006). As previously discussed, our results appear to be consistent with the hypothesis that resource availability ultimately controls invasibility, because plots with more open space, and thus more available resources early in the growing season, were more invaded. By this reasoning, we would also expect a positive relationship between soil depth and invasion successbecause soil depth is associated with the niche axis of waterand nutrient acquisition (Dimitrakapoulos \& Schmid 2004), especially in grassland ecosystems (Whittaker 1954; Davies et al. 2007; Moore \& Elmendorf 2011; Baer et al. 2003; Dornbrush \& Wilsey 2010). The strong positive relationship 
between productivity and soil depth independent of both loss order and richness level is further evidence that greater soil depth confers more below-ground resources in our experimental system.

It is thus somewhat surprising that soil depth was a significant predictor of invasion success only in the randomized assemblages, despite a positive trend of invader biomass with soil depth in the realistic assemblages. We suspect that the strong, inverse relationship between species richness and invader biomass in the realistic species loss order confers high variability of invader biomass within each soil depth level (across richness levels), which leads to a more diffuse, and ultimately insignificant, main effect of soil depth.

Both the strong negative effect of increasing species richness on invasibility in the realistic species loss scenario and the positive effect of increasing soil depth on invasibility in the randomized species loss scenario are consistent with the fluctuating resource availability hypothesis (Davis, Grime \& Thompson 2000), which posits that any mechanism providing an increase in resource availability (either over time or, in our case, across space) reduces competition intensity and promotes invasion. Our results demonstrate that the relative strength of these two mechanisms (species richness and soil depth) depends on the order in which species are lost. This conclusion emerged only because of our direct comparative approach; if we had examined the functional consequences of either realistic or randomized species losses in isolation, we would have come to different conclusions about the factors controlling invasion success in this ecosystem.

\section{Conclusions}

We have attempted to incorporate more realism than is common in manipulative BEF experiments by conducting a fieldbased experiment using a non-random species loss scenario associated with drought as a driver of biodiversity change and by taking advantage of variation in soil depth to examine the influence of environmental heterogeneity on the relationship between biodiversity and ecosystem functioning. Widespread stressors other than prolonged drought (e.g. eutrophication, habitat fragmentation) might lead to different, non-random patterns of species loss and thus to different effects on ecosystem functioning. Moreover, it is not possible to know to what extent exclusion of herbivory and preliminary clearing of experimental plots might have influenced our results. Nonetheless, our results have several implications, each of which demonstrate the value of incorporating realistic species loss orders into manipulative BEF experiments. First, neither invasion resistance nor above-ground productivity responded to randomized species losses in this ecosystem. Only a realistic loss order exposed the influence of biodiversity losses on these key ecosystem processes, highlighting the fact that observed patterns of community composition changes or species losses in real ecosystems can have distinct functional consequences from randomized losses (Solan et al. 2004; Zavaleta \& Hulvey 2004, 2007; Bunker et al. 2005; Bracken et al. 2008). Second, our results demonstrate that realistic species losses can over- whelm the effects of abiotic drivers of invasion, in this case variation in soil depth, which were otherwise significant in adjacent randomized species loss plots. Finally, our findings provide further evidence that a specific driver of biodiversity loss (drought sensitivity) can selectively affect species with particular traits (such as species with an annual life history versus a perennial life history, $c f$. Tilman \& El Hadi 1992), bolstering previous findings (e.g. Zavaleta \& Hulvey 2004; Bracken et al. 2008) in support of the general expectation that realistic species losses will have stronger effects on ecosystem functioning than randomized losses. Additional research comparing loss orders generated by different drivers, and their effects on different ecosystem processes, will shed more light on how biodiversity losses in response to multiple stressors might affect the functioning of ecosystems.

\section{Acknowledgements}

We thank Alex Schrock, Alison McGregor, Matt Meckel, Rebecca John and Tim Lipovsky for assistance in the field and in the laboratory. Blair McLaughlin, Nicole Heller, Richard Hobbs, Stuart Weiss, and the members of the Zavaleta laboratory improved the study design and manuscript. We thank Peter Alpert and three anonymous reviewers for comments that greatly improved the quality of this manuscript. This research was funded by the Andrew W. Mellon Foundation and the National Science Foundation (DEB-0719241 and DEB0918715).

\section{References}

Albertson, F.W. \& Weaver, J.E. (1944) Nature and degree of recovery of grassland from the great drought of 1933 to 1940. Ecological Monographs, 14, 393-479.

Atmar, W. \& Patterson, B.D. (1993) The measure of order and disorder in the distribution of species in fragmented habitat. Oecologia, 96, 373-382.

Baer, S.G., Blair, J.M., Collins, S.L. \& Knapp, A.K. (2003) Soil resources regulate productivity in newly established tallgrass prairie. Ecology, 84, 724735 .

Bracken, M.E.S. \& Nielsen, K.J. (2004) Diversity of intertidal macroalgae increases with nitrogen loading by invertebrates. Ecology, 85, 2828-2836.

Bracken, M.E.S., Friberg, S., Gonzalez-Dorantes, C. \& Williams, S. (2008) Functional consequences of realistic biodiversity changes in a marine ecosystem. Proceedings of the National Academy of Sciences, 105, 924.

Bunker, D., DeClerck, F., Bradford, J.C., Colwell, R.K., Perfecto, I., Phillips, O.L., Sankaran, M. \& Naeem, S. (2005) Species loss and aboveground carbon storage in a tropical forest. Science, $\mathbf{3 1 0}, 1029$.

Cardinale, B.J. (2011) Biodiversity improves water quality through niche partitioning. Nature, 472, 86-89.

Cardinale, B.J., Matulich, K.L., Hooper, D.U., Byrnes, J.E., Duffy, E., Gamfeldt, L., Balvanera, P., O'Connor, M.I. \& Gonzalez, A. (2011) The functional role of producer diversity in ecosystems. American Journal of Botany, 98, 572-592.

Chapin III, F.S., Zavaleta, E.S., Eviner, V.T., Naylor, R.L., Vitousek, P.M., Reynolds, H.L., Hooper, D.U., Lavorel, S., Sala, O.E., Hobbie, S.E., Mack, M.C. \& Díaz, S. (2000) Consequences of changing biodiversity. Nature, 405, 234-242.

Dai, A. (2011) Drought under global warming: a review. Wiley Interdisciplinary Reviews. Climate Change, 2, 45-65.

Davies, K.F., Harrison, S., Safford, H.D. \& Viers, J.H. (2007) Productivity alters the scale dependence of the diversity-invasibility relationship. Ecology, 88, 1940-1947.

Davis, M.A., Grime, J.P. \& Thompson, K. (2000) Fluctuating resources in plant communities: a general theory of invasibility. Journal of Ecology, 88, 528-534.

Dimitrakapoulos, P.G. \& Schmid, B. (2004) Biodiversity effects increase linearly with biotope space. Ecology Letters, 7, 574-582.

Dornbrush, M.E. \& Wilsey, J.E. (2010) Experimental manipulation of soil depth alters species richness and co-occurrence in restored tallgrass prairie. Journal of Ecology, 98, 117-125. 
Duffy, J.E., Srivastava, D.S., McClaren, J., Sankaran, M., Solan, M., Griffin, J., Emmerson, M. \& Jones, K.E. (2009) Forecasting decline in ecosystem services under realistic scenarios of extinction. Biodiversity, Ecosystem Functioning, and Human Wellbeing (eds S. Naeem, D.E. Bunker, A. Hector, M. Loreau \& C. Perrings), pp. 60-77. Oxford University Press Inc, Oxford, UK.

Dukes, J.S. (2001) Biodiversity and invasibility in grassland microcosms. Oecologia, 126, 563-568.

Elton, C.S. (1958) The Ecology of Invasions by Animals and Plants. Methuen, London.

Going, B.M., Hillerislambers, J. \& Levine, J.M. (2009) Abiotic and biotic resistance to grass invasion in serpentine annual plant communities. Oecologia, 159, 839-847.

Hautier, Y., Niklaus, P.A. \& Hector, A. (2009) Competition for light causes plant biodiversity loss after eutrophication. Science, 324, 636-638.

Hector, A., Dobson, K., Minns, A., Bazeley-White, E. \& Lawton, J.H. (2001) Community diversity and invasion resistance: an experimental test in a grassland ecosystem and a review of comparable studies. Ecological Research, 16, 819-831.

Hillebrand, H., Bennett, D.M. \& Cadotte, M.W. (2008) Consequences of dominance: a review of evenness effects on local and regional ecosystem processes. Ecology, 89, 1510-1520

Hillebrand, H. \& Matthiessen, B. (2009) Biodiversity in a complex world: consolidation and progress in functional biodiversity research. Ecology Letters, 12, 1405-1419.

Hobbs, R.J., Yates, S. \& Mooney, H.A. (2007) Long-term data reveal complex dynamics in grassland in relation to climate and disturbance. Ecological Monographs, 77, 545-568.

Hooper, D.U. (2011) Biodiversity, ecosystem functioning, and global change. Serpentine: The Evolution and Ecology of a Model System (eds S. Harrison \& N. Rajakaruna), pp. 329-357. University of California Press, Berkeley, CA.

Hooper, D.U. \& Vitousek, P.M. (1998) Effects of plant composition and diversity on nutrient cycling. Ecological Monographs, 68, 121-149.

Hooper, D.U., Chapin III, F.S., Ewel, J.J., Hector, A., Inchausti, P., Lavorel, S. et al. (2005) Effects of biodiversity on ecosystem functioning: a consensus of current knowledge. Ecological monographs, 75, 3-35.

Levine, J.M., Adler, P.B. \& Yelenik, S.G. (2004) A meta-analysis of biotic resistance to exotic plant invasions. Ecology Letters, 7, 975-989.

Losure, D.A., Wilsey, B.J. \& Moloney, K.A. (2007) Evenness-invasibility relationships differ between two extinction scenarios in tallgrass prairie. Oikos, 116, 87-98.

Miklòs, I. \& Podani, J. (2004) Randomization of presence-absence matrices: comments and new algorithms. Ecology, 85, 86-92.

Millennium Ecosystem Assessment (2005) Ecosystems and Human Well-being: Biodiversity Synthesis. World Resources Institute, Washington, DC

Moore, K.A. \& Elmendorf, S.C. (2011) Plant competition and facilitation in systems with strong environmental gradients. Serpentine: The Evolution and Ecology of a Model System (eds S. Harrison \& N. Rajakaruna), pp. 223-236. University of California Press, Berkeley, CA.

Naeem, S. (2008) Advancing realism in biodiversity research. Trends in Ecology \& Evolution, 23, 414-416.

Pimm, S.L., Russell, G.J., Gittleman, J.L. \& Brooks, T.M. (1995) The future of biodiversity. Science, 269, 347-350.

Renne, I.J., Tracy, B.F. \& Colonna, I.A. (2006) Shifts in grassland invasibility: effects of soil resources, disturbance, composition, and invader size. Ecology, 87, 2264-2277.
Rodríguez-Gironés, M. \& Santamaría, L. (2006) A new algorithm to calculate the nestedness temperature of presence-absence matrices. Journal of Biogeography, 33, 924-935.

van Ruijven, J. \& Berendse, F. (2005) Diversity-productivity relationships: initial effects, long-term patterns, and underlying mechanisms. Proceedings of the National Academy of Sciences, 102, 695-700.

Schläpfer, F., Pfisterer, A.B. \& Schmid, B. (2005) Non-random species extinction and plant production: implications for ecosystem functioning. Journal of Applied Ecology, 42, 13-24.

Solan, M., Cardinale, B.J., Downing, A.L., Englehardt, K.A.M., Ruesink, J.L. \& Srivastava, D.S. (2004) Extinction and ecosystem function in the marine benthos. Science, 306, 1177-1180.

Stachowicz, J.J., Fried, H., Osman, R.W. \& Whitlatch, R.B. (2002) Biodiversity, invasion resistance, and marine ecosystem function: reconciling pattern and process. Ecology, 83, 2575-2590.

Tilman, D. (1999) The ecological consequences of changes in biodiversity: a search for general principles. Ecology, 80, 1455-1474.

Tilman, D. \& El Hadi, A. (1992) Drought and biodiversity in grasslands. Oecologia, 89, 257-264.

Ulrich, W., Almeida-Neto, M. \& Gotelli, N. (2009) A consumer's guide to nestedness analysis. Oikos, 118, 3-17.

Weiss, S.B. (1999) Cows, cars, and checkerspot butterflies: nitrogen deposition and management of nutrient-poor grasslands for a threatened species. Conservation Biology, 13, 1476-1486.

Whittaker, R.H. (1954) The ecology of serpentine soils. Ecology, 35, 258-288.

Zavaleta, E.S. \& Hulvey, K.B. (2004) Realistic species losses disproportionately reduce grassland resistance to biological invaders. Science, 306, 1175-1177.

Zavaleta, E.S. \& Hulvey, K.B. (2007) Realistic variation in species composition affects grassland production, resource use and invasion resistance. Plant Ecology, 188, 39-51.

Zavaleta, E., Pasari, J., Moore, J., Hernandez, D., Suttle, K.B. \& Wilmers, C.C. (2009) Ecosystem responses to community disassembly. Annals of the New York Academy of Sciences, 1162, 311-333.

Received 17 May 2011; accepted 8 December 2011

Handling Editor: Peter Alpert

\section{Supporting Information}

Additional Supporting Information may be found in the online version of this article:

Figure S1. Annual precipitation for the years 1960-2009 at Coyote Ridge, CA estimated using the parameter-elevation regressions on independent slopes model (PRISM; http://prism.oregonstate.edu).

As a service to our authors and readers, this journal provides supporting information supplied by the authors. Such materials may be re-organized for online delivery, but are not copy-edited or typeset. Technical support issues arising from supporting information (other than missing files) should be addressed to the authors. 